\title{
Collective Trust within Organizations: Conceptual Foundations and Empirical Insights
}

\author{
Roderick M. Kramer \\ Graduate School of Business, Stanford University, Stanford, USA
}

\begin{abstract}
This paper introduces a conception of collective trust applied to organizational settings. In contrast with widely studied interpersonal forms of trust, collective trust is conceptualized as a kind of generalized trust conferred on other organizational members. The paper elaborates on the psychological, relational, and structural underpinnings of collective trust. It then explicates individual and organizational consequences. The paper also discusses methodological approaches to studying collective trust, ranging from laboratory simulations to field-based, qualitative studies. Representative findings from such studies are summarized.

Corporate Reputation Review (2010) 13, 82-97. doi:10.1057/crr.2010.9
\end{abstract}

KEYWORDS: collective trust; cooperation; organizational trust; social capital; social identity; trust

\section{INTRODUCTION}

More than 200 years ago, the British Empiricist David Hume offered this insightful analysis regarding the psychological foundations of our trust in others and the beneficial consequences that flow from such trust:

When each individual perceives the same sense of interest in all his fellows, he immediately performs his part of any contract, as being assur'd that they will not be wanting in theirs. All of them, by concert, enter into a scheme of actions, calculated for common benefit, and agree to be true to their words; nor is there anything requisite to form this concert or connection, but that everyone have a sense of interest in the faithful fulfilling of engagements, and express that sense to other members of the society. (Hume, 1969)

Hume's observations regarding the foundations of mutual trust and collective action has a surprisingly contemporary relevance and resonance, as many organizations and institutions struggle with problems of this very nature. His analysis also directs our attention to the role positive social expectations play in the emergence of collective behavior: Because trusting others creates vulnerability, anything that provides grounds for mutual assurance might help reduce that perceived vulnerability.

In the present paper, I pursue these ideas of vulnerability and assurance from the standpoint of social psychological and organizational research on the relational underpinnings of trust. In particular, I present some theoretical ideas regarding a form of generalized trust found in organizational settings. I characterize this generalized trust as collective trust. In contrast with interpersonal trust - the target of which is another specific individual - the distinctive characteristic of collective trust is that its target is the organization and its collective membership taken as a whole. In other
Corporate Reputation Review,
Vol. 13, No. 2, pp. 82-97

(C) 2010 Macmillan Publishers Ltd. 1363-3589 
words, the cognitive unit is a larger social aggregate, defined and bounded by common membership in the organization. Second, I suggest how we might conceptualize such collective trust. Third, I review evidence regarding the foundations on which such generalized trust in other organizational members might be predicated.

To foreshadow one of the primary conclusions I wish to reach, I argue that collective trust arises when a variety of institutional, social and psychological elements are in place. Loosely construed, collective trust constitutes a kind of psychological tippingpoint phenomenon: when sufficient reassuring factors are perceived to be in place, collective trust tends to be present. When they are insufficient or absent, it does not. There are, I assume, multiple configurations of such factors, but some threshold of such confluent factors is assumed to be necessary in order to tip the prototypic organizational member toward trusting others. A basic research question this paper addresses is, 'What are the conditions under which such trust thrives?'

Throughout this paper, I emphasize the presumptive nature of collective trust because it is based, I will propose, on the kinds of social understandings - both explicit and tacit - that move decision-makers toward a willingness to engage in trusting behavior when dealing with others, especially in the absence of the sort of individualized, personal knowledge about others that usually constitutes a foundation for such risky behavior. In the place of individuating knowledge about specific others, collective trust is predicated on schematic knowledge and stereotypic beliefs regarding the organization and what membership in it presumably tells us about other members' trust-related motives, intentions, and likely actions. In this respect, collective trust is treated here as a cognitive construct.

To explore these issues, this papers several issues. First, how might we conceptualize such collective trust? Second, what can we say about the foundations or bases upon which such trust might be based? Third, what are the special methodological issues, if any, to consider when we attempt to study such trust?

\section{CONCEPTUALIZING COLLECTIVE TRUST IN ORGANIZATIONAL CONTEXTS}

The benefits of trust within organizational settings have been elaborated at some length elsewhere (Bachmann and Zaheer, 2006; Bromiley and Cummings, 1995; Fukuyama, 1995; Gambetta, 1988; Kramer and Cook, 2006; Lane and Bachmann, 1998). Thus, it is not necessary to repeat them here, other than to note that a well-documented relationship exists between individuals' trust in other people and their willingness to engage in trust-related behavior when interacting with them. In elaborating on the circular and inherently self-reinforcing nature of this vital relationship, Putnam (1993) observed, 'The greater the level of trust within a community, the greater the likelihood of cooperation. And cooperation itself breeds trust' (p. 171). Thus, stated in slightly different terms, positive expectations about others facilitate positive behaviors when interacting with them; those behaviors, in turn, strengthen positive expectations; hence, a virtuous cycle in which expectation and action collude to create and reinforce desired outcomes.

\section{Preliminary Considerations}

In the context of simple, dyadic relationships, the underpinnings of such virtuous cycles have been elaborated at some length (eg, Lindskold, 1978). To a large extent, much of this previous research has construed the development of individuals' positive expectations regarding others' trustworthiness as history-dependent processes (Boon and Holmes, 1991; Deutsch, 1958; Pilisuk and Skolnick, 1968; Gabarro, 1978; Solomon, 1960; Weber et al., 2005; Whitener et al., 2006). According to such models, trust 
between two interdependent actors thickens or thins as a function of their cumulative interactions. Interactional histories give decision-makers information that is useful in assessing others' dispositions, intentions, and motives. This information, in turn, provides a basis for drawing inferences regarding their trustworthiness and for making predictions about their future behavior. Evidence of the importance of such interactional histories comes from a substantial body of experimental research linking specific patterns of behavioral interaction with changes in trust (Deutsch, 1958; Lindskold, 1978; Pilisuk et al., 1971; Pilisuk and Skolnick, 1968).

Such models posit that interactional histories become a basis for initially calibrating and then updating trust-related expectations. Boyle and Bonacich's (1970) analysis of trust development is representative of such arguments. Individuals' expectations about trustworthy behavior, they posit, tend to change 'in the direction of experience and to a degree proportional to the difference between this experience and the initial expectations applied to it' (p. 130). In this regard, history-based trust can be construed as an important form of knowledge-based or personalized trust in organizations (Lewicki and Bunker, 1995; Shapiro et al., 1992).

As we move from the simple dyadic case to more complex multi-actor or collective contexts, however, it isn't entirely clear that this sort of deep, historical, or 'thick' interpersonal trust will necessarily generalize readily or fully to a larger aggregate or collection of interdependent social actors. In such collective contexts, individuals may be just as deeply interdependent with, and dependent on, other people, but they are unlikely to have the requisite detailed, personal knowledge of each other that provides the usual foundation for interpersonal trust. Instead, they must interact with myriad others, often on the basis of scant individuating information, transient goals, infrequent contact, and only superficial familiarity.

Recognizing this conceptual chasm between interpersonal and collective forms of trust, Putnam (1993) commented, 'Trust entails a prediction about the behavior of an independent actor. In small, close-knit communities, this prediction is based on what Bernard Williams calls 'thick trust', that is, a belief that rests on intimate familiarity with this individual. In larger, more complex settings, however, a more impersonal or indirect form of trust is required' (p. 171, emphases added).

It is precisely this less personal, less individuated, and less direct form of trust that has engaged me as a conceptual problem. In particular, there are several specific questions that have preoccupied me as a social psychologist interested in trust. First, what might be the psychological contours of such impersonal trust? Second, and relatedly, how does impersonal trust differ from the more widely studied 'thick' forms of trust? Also, what can we say about the foundations of such 'thin' trust?

\section{Collective Trust as a Positive Social Expectation}

As Hardin (2002) aptly noted in a recent assessment of the trust literature, scholars often talk about trust in elliptical terms, as if it were simply a belief, attitude, or disposition of a social perceiver. However, this way of talking about trust is really merely convenient shorthand for describing what is inherently a complex three-part relationship between a social perceiver and the object or target of his or her target. Specifically, trust involves a truster (the subject rendering a trust judgment), a trustee or set of trustees (the object or targets of that judgment), and a specific domain or context within which trust judgments arise or apply. Thus, medical patients might fully trust their surgeons with respect to any surgical recommendations they might have, but not trust them 
at all with respect to their financial advice, simply and only because the domain of expertise of the physician is not viewed as encompassing that domain.

In the case of the simplest trust relation - dyadic trust - we obviously have one specific truster and one designated trustee involved in some sort of interdependent relationship. In the case of a patient's trust in her physician, for example, the foundations of that trust might be predicated on such things as (1) the specific training and institutional affiliation of the physician; (2) the history of interpersonal interaction (favorable or not) between them; (3) the reputation of the medical institution employing the physician and within which the patient's care is provided; and (4) the nature of the medical complaint or malady. Thus, a patient with cervical cancer might trust a physician who was trained at Harvard Medical School, is affiliated with the Mayo Comprehensive Cancer Center, and has specific expertise in gynecologic oncology.

In the case of generalized trust perceptions and judgments within larger social aggregates - such as a group or organization - the judgmental foundations or underpinnings of trust become more complicated. Obviously, there are multiple trusters, multiple trustees, and multiple domains onto which their trust concerns may be mapped. There may also be important power-status differences and resource dependencies between interdependent actors, which further complicate trust-related information processing, and judgment. As a consequence, the particular evidentiary grounds on which trust is predicated in collective contexts are less obvious and clear-cut. Nonetheless, actors still typically possess some general set of beliefs and expectations regarding the trustworthiness of the 'average' or prototypic other within the group or organization.

One way of conceptualizing this general level of trust in these other prototypic organizational members, then, is as a form of generalized expectation conferred on the aggregate or collective. In short, it constitutes a sort of diffuse cognitive expectation (insofar as its object or target is a social aggregate that encompasses all the members of the collective). It is also a bounded expectation, insofar as it applies only to those individuals who are considered 'in-group' members (included in the relevant social boundary or category). I characterize this bounded organizational trust, then, as a form of generalized expectation or belief that is predicated upon, and co-extensive with, shared membership in an organization. I view it as a presumptive psychological state or orientation because it represents a sort of background expectation that individuals have about other organizational members. In this sense, it can acquire over time a taken-for-granted quality (of exactly the sort Hume that posits).

\section{STUDYING COLLECTIVE TRUST: METHODOLOGICAL CONSIDERATIONS}

There are a variety of different approaches a researcher might take when exploring the antecedents and consequences of collective trust. Experimental analogs can be created to study collective cognition and choice behavior within laboratory settings, and a variety of such analogs have been used in past research (eg, Kollock, 1994; Kramer, 1998; Messick et al., 1983). Surveys can be use to assess attitudinal and behavioral correlates of generalized trust (Pew Research Center, 1996). Ethnographic observation constitutes another rich source of evidence (Fine and Holyfield, 1996).

The trade-offs with respect to the internal versus external validity of these methods are well known (Crano and Brewer, 2002). Thus, I won't discuss them explicitly here, other than to emphasize the advantages of a multi-method approach. If convergent validity is the researcher's ultimate goal, then the use of multiple methods is highly recommended. In my own work, summarized 
throughout this paper, I've tried to adopt precisely such a multi-method approach (a review of these studies is provided in Kramer, 2009c). Thus, my colleagues and I started with laboratory experiments to test the causal significance of theorized variables such as common fate and shared social identities using experiments, using undergraduate students as study participants (summarized in Kramer and Brewer (1986) and also Kramer et al. (1996)). We then turned to the use of computer-based tournaments, using expert decision-makers (Bendor et al., 1991). More recently, we've found it useful to investigate more directly how people actually think about trust dilemmas in the organizational settings in which they actually work (eg, Cook et al., 2004). These settings include, for example, studying the grounds for collective trust in a variety of public institutions and private organizations. These include the Oval Office, Hollywood film studios, talent agencies, sales organizations, hi-tech companies and special effects firms, grocery stores, and medical care settings.

Although these field sites presented themselves opportunistically, I wouldn't characterize them as necessarily 'convenience samples'. More often than not, I found, assessing sensitive issues of trust and distrust in real-world settings turns out to be anything but convenient. Many organizations are loath to admit problems with trust. Thus, they tend (and not inappropriately so) to be extremely wary of outside interventions or intrusions - even purely observational ones. And even those organizations which do not perceive themselves as having problems with trust, I found, are often quite reluctant to allow outsiders in - they intuit the possibility that outsiders might, in their probes, disturb a valued but potentially fragile equilibrium. 'Why risk rocking a boat that is sailing smoothly?' one executive suggested to me when turning down my request to study trust relations in his organization (one that enjoyed a great reputation on this dimension). On balance, though, the effort is worth it: I believe we learn a great deal by intensive field observation and openended conversations with real people talking about the real trust dilemmas they confront in their very real work places.

\section{Relational and Structural Underpinnings of Collective Trust: A Review of the Empirical Evidence}

Social scientists have afforded considerable attention to identifying the foundations or bases of trust within organizations (eg, Arrow, 1974; Cook, 2001; Cook et al., 2005; Creed and Miles, 1996; Granovetter, 1985; McEvily et al, 2006; Zucker, 1986). The quotation by David Hume, introduced at the beginning of this paper, clearly suggests the importance of individuals' a priori beliefs or expectations regarding other group members' trustworthiness in shaping their own willingness to engage in trusting behaviors themselves. When the requisite assurances are in place, Humes argues, the path to mutual trust and resultant cooperation is paved. But what are the grounds for such assurances? On what basis do individuals entertain such positive expectations regarding other organizational members?

My research on this question has adopted a social information processing perspective. According to Salancik and Pfeffer's (1978) original formulation of this perspective, in order to understand people's behavior in organizations, it is essential to consider the social context within which that behavior is embedded. 'One can learn most about individual behavior', they posit, 'by studying the informational and social environment within which that behavior occurs and to which it adapts' (p. 226). One reason context is so crucial, Salancik and Pfeffer go on to argue, is that it directs our attention toward certain information 'making that information more salient and providing expectations concerning individual behavior and the 
logical consequences of such behavior' (p. 227). According to this perspective, then, we can understand people's decisions to engage in trusting behavior (or any other form of social behavior for that matter) by paying attention to what information they attend to and also, of course, how they interpret or construe that information.

This guiding assumption has led me to think about trust behavior from the perspective of what I term the vigilant social auditor (Kramer, 1998). The vigilant social auditor is presumed, all else equal, to be a motivated social perceiver, interested in rendering sensible and productive judgments about others' trustworthiness. Thus, the individual engages in trust acts when sufficient grounds are perceived to be present, and avoids such acts when they are perceived to be missing.

Rule systems constitute a primary and important mechanism for providing the kinds of shared assurances that facilitate trusting behavior in collective contexts. By a rule system, we mean simply a set of formal and informal understandings that govern how individuals within the organization interact. As March (1994) argued, organizational rules contribute in many ways to members' positive expectations about others' behavior. In this sense, rules constitute a set of normative or institutionalized expectations regarding one's own and other's range of acceptable or anticipated actions. Rule-based trust, I should note, is not predicated on members' attempts to predict others' specific trustrelated behaviors or outcomes, but rather on their understandings - presumed to be prevalent or shared - regarding the binding structure of rules guiding - and constraining - others' behavior. As March and Olsen (1989) posited along these lines, rule-based trust is sustained within an organization 'not [by] an explicit contract ... [but rather] by [members'] socialization into the structure of rules' (p. 27).
As a consequence, when reciprocal confidence in members' socialization into, and continued adherence to, a normative rule system is high, mutual trust acquires a takenfor-granted quality. Along these lines, and as one example, the supermarket Whole Foods has created an elaborate system of rules among its employees that help shape their positive expectations regarding the organization and the behavior of its members (eg, members are organized into teams and teams are empowered to hire new members themselves, rather than having this function managed by a traditional human resource department). Thus, they can interview individuals extensively before hiring them, and getting a sense for how the person might fit into the value system of the organization. When asked about trust and trustworthy behavior at one store, an employee put it to me this way, 'It [trustworthy behavior] is just expected of others - and it is expected of you as well. You don't have to worry about it because you can count on it'.

Fine and Holyfield (1996) provide another nice illustration of how a set of explicit rules, and the tacit understandings they produce, can function to create and sustain high levels of collective trust within an organization. Their study examined the bases of trust in the Minnesota Mycological Society, an organization that consists of amateur mushroom aficionados. This organization provided a rich setting in which to study the bases of trust for several reasons. First, the costs of misplaced trust in this organization can be quite severe: eating a mushroom that someone else in the organization has mistakenly declared safe for consumption can lead to serious illness and even, in rare instances, death. Given such risks, Fine and Holyfield noted, credibility is lost only once unless a mistake is reasonable. Consequently, members are likely to be highly vigilant when it comes to assessing and maintaining mutual trust and trustworthiness. Second, because membership 
in the organization is voluntary, exit is comparatively costless. If doubts about others' trustworthiness become too great, therefore, members will take their trust elsewhere and the organization will simply die. Thus, the organization's survival depends upon its ability to successfully instill and sustain perceptions of mutual trustworthiness among its members.

Fine and Holyfield identified three important bases of trust within this organization, which they termed awarding trust, managing risk, and transforming trust. One way trust is created, they observed, is to award trust to others even when confidence in them may be lacking. For example, considerable social pressure is exerted on novices to consume dishes at banquets prepared by other members. As Fine and Holyfield put it, there is an insistence on trust. Thus, even if members remain privately anxious, their public behaviors (even if somewhat coerced) connote high levels of trust. Collectively, these behavioral displays of trust in other members constitute a potent form of social proof to members that their individual acts of trust are sensible.

This insistence on trust is adaptive, of course, only if collective trustworthiness is, in fact, actually in place or warranted. Accordingly, a second crucial element in the management of trust within this organization occurs through practices and arrangements that ensure competence and due diligence. This result is achieved partially through the meticulous socialization processes that newcomers to the organization are subjected to. Novices participate in these socialization processes with appropriate levels of commitment because it helps them manage the risks of mushroom eating and also to secure a place in the social order of the group. In turn, more seasoned organizational members teach novices out of a sense of obligation, having benefitted from the instruction from those who came before them. This repayment or reciprocation constitutes an interesting sort of transgenerational positive social expectation.

Over time, Fine and Holyfield argued, as members acquire knowledge about the organization, the nature of trust itself is transformed. Early on, the organization is simply [in their terminology] a 'validator' of trust for new members. Over time, however, it becomes an 'arena in which trusting relations are enacted and organizational interaction serves as its own reward' (p. 29). As with trust in engineers, this form of trust is not simply trust in the expertise of specific individuals, but more importantly, trust in a system of expertise. And that system, in turn, is embodied in a well-thought out system of rules which members believe to be efficacious.

Another way in which rules foster trust is through their influence not only on individuals' expectations regarding other members' behaviors, but also their expectations regarding their own behavior (ie, their self-perceptions). As March (1994) observed in this regard, organizations function much like 'stage managers' by providing 'prompts that evoke particular identities in particular situations' (p. 72). Miller (1992) offered an excellent example of this kind of socially constructed, and ultimately self-reinforcing, dynamic. In discussing the underpinnings of mutual trust and cooperation at HewlettPackard (HP), he noted that, 'The reality of cooperation is suggested by the open lab stock policy, which not only allows engineers access to all equipment, but encourages them to take it home for personal use' (p. 197).

From a strictly economic perspective of course, HP's policy simply reduces monitoring and transaction costs. However, from the standpoint of a rule-based unde standing of trust-related transactions, its consequences are more subtle and pervasive. As Miller (1992) observed, 'The open door symbolizes and demonstrates management's trust in the cooperativeness of the employees' 
(p. 197). Because such acts are so manifestly predicated on trust in others, moreover, they tend to breed trust in turn. As with many forms of social behavior, trust is governed by general expectations of reciprocity: all else equal, if you trust me, I ought to trust you. In interviews that I did with HP employees in 1984-1985, I observed many examples of this sort of trust.

Rule-based practices of this sort can exert subtle but powerfully self-reinforcing influences on expectations, shaping not only individuals' perceptions of their own honesty and trustworthiness, but also their expectations and beliefs regarding other organizational members' general honesty and trustworthiness as well. As Miller noted in this regard, by eliminating time clocks and locks on equipment room doors at HP, the organization built 'a shared expectation among all the players that cooperation will most likely be reciprocated' (emphases added). The result, he went on to argue, is 'a shared common knowledge in the ability of the players to reach cooperative outcomes' (p. 197). Thus, by institutionalizing trust (and trustworthiness) through rule-based practices at the macro-organizational level, trust becomes internalized at the microorganizational (individual) level. In this fashion, rule-based trust becomes a potent form of 'expectational asset' (Knez and Camerer, 1994) that facilitates more spontaneous cooperation among organizational members.

Role-based trust represents a closely related and additional basis for presumptive trust in others. Role-based trust constitutes a form of impersonalized trust, insofar as it is predicated on knowledge that a person occupies a particular role in the organization rather than on specific knowledge regarding his or her capabilities, dispositions, motives, or intentions. Roles can serve as proxies for personalized knowledge about other organizational members in several ways. First, as Barber (1983) noted, strong expectations regarding technically competent role performance are typically aligned with roles in organizations in ways that work reasonably well: role occupants are expected to fulfill the fiduciary responsibilities and obligations associated with the roles they occupy and frequently do. Thus, to the extent that people within an organization have confidence in the fact that role occupancy signals both (1) an intent and motivation to fulfill such obligations; and (2) the competence required for carrying them out, individuals can adopt a sort of presumptive trust based upon knowledge of role occupancy and the system of role relations, even in the absence of personalized knowledge about the individual in the role or history of prior interaction.

Unpacking this logic a bit, numerous scholars (Barber, 1983; Dawes, 1994; Meyerson et al., 1996) have noted, it is not the person in the role that is trusted so much as the system of expertise that produces and maintains the role-appropriate behavior of role occupants. As Dawes (1994) aptly observed in this regard, 'We trust engineers because we trust engineering and believe that engineers are trained to apply valid principles of engineering' (p. 24). Moreover, Dawes notes, 'We have evidence every day that these principles are valid when we observe airplanes flying' (p. 24). The strength of such trust arises from, and is sustained by, people's common knowledge or beliefs regarding such things as (1) the severity of barriers to entry into the organizational role (ie, the selectivity of the organization); (2) their presumptions regarding the adequacy and effectiveness of the training and socialization processes that role occupants undergo; and (3) their perceptions of various accountability mechanisms intended to ensure ongoing role compliance.

As with the other foundations for generalized trust, role-based trust functions to reduce uncertainty regarding role occupant's trust-related intentions and capabilities. They thus lessen the perceived need to 
negotiate trust when interacting with role occupants: if you're in the role, you're obviously up to the task.

Interestingly, unlike other forms of trust, role-based trust may actually benefit from the absence of personalized knowledge about others (Meyerson et al., 1996). Personalized knowledge can interfere with, and in some cases even undermine, trust (eg, in a recent plane crash, the cockpit recordings revealed the pilot and co-pilot sharing thoughts about their lack of experience, as well as their doubts concerning their ability to deal with the circumstances - icing - they were confronting).

Category-based trust constitutes another substitute or proxy for individualized knowledge about others (Orbell et al., 1994). Categorybased trust refers to trust predicated on information regarding a trustee's membership in a social or organizational category - information which, when salient, often unknowingly influences others' judgments about their trustworthiness. As Brewer (1981) noted, there are a number of reasons why membership in a salient category can provide a basis for presumptive trust. First, shared membership in a given category can serve as a 'rule for defining the boundaries of low-risk interpersonal trust that bypasses the need for personal knowledge and the costs of negotiating reciprocity' when interacting with other members of that category (p. 356). Further, because of the cognitive consequences of categorization and in-group bias, individuals tend to attribute positive characteristics such as honesty, cooperativeness, and trustworthiness to other in-group members (Brewer, 1996). As a consequence, individuals may confer a sort of what she terms depersonalized trust on other in-group members that is predicated simply on the basis of awareness of their shared category membership.

Transitive trust constitutes another alternative to a history of direct, personal interaction or knowledge. Transitive trust is a solution predicated by reducing or mitigating our uncertainty about one target's trustworthiness by drawing on, or benefitting from, our knowledge of another's demonstrated trustworthiness. I characterize this form of trust as transitive because it facilitates transferring positive expectations from one (known) target to another (lesser known) one. Appreciating both the importance of information regarding others' trustworthiness and the problem of uncertainty about such information, Burt and Knez (1995) argued that third parties in organizations are important conduits of trust because of their ability to diffuse trust-relevant information via gossip. As they demonstrated in a study of trust among managers in a high tech firm, gossip constitutes a valuable source of 'second-hand' knowledge about others. However, the effects of gossip on trust judgments are complex and not always in the service of rational assessment of others' trustworthiness. Part of the problem, Burt and Knez theorized, is that third parties tend to make only partial disclosures about others. In particular, third parties often communicate incomplete and skewed accounts regarding the trustworthiness of a prospective trustee because people prefer to communicate information consistent with what they believe the other party wants to hear. Consequently, when a person has a strong relation to a prospective trustee, third parties tend to convey stories and information that corroborate and strengthen the tie, therefore increasing certainty about the person's trustworthiness. Thus, third parties tend to amplify such trust.

The most important or informationally relevant kinds of third parties are those who are members of our networks or otherwise trusted networks. Uzzi's (1997) study of exchange relations among networked firms in the New York apparel industry, described earlier, provides further evidence of the crucial role third parties play in the development and diffusion of trust. He found that 
third parties acted as important 'gobetweens' in new relationships enabling individuals to 'roll over' their expectations from well-established relationships to others in which adequate knowledge or history was not yet available. In explaining how this worked, Uzzi argued that go-betweens transfer expectations and opportunities of existing embedded relationships to newly formed ones thereby 'furnishing a basis for trust and subsequent commitments to be offered and discharged' (p. 48).

If collective trust is grounded, in part, on a confluence of signals indicating the reasonableness of trust, then the signals that organizational leaders send constitute an especially potent source of trust. Leaders tend to be focal points for organizational sense making and subordinates, not unreasonably, often pay a great deal of attention to what those at the top do - and don't do (Kramer, 1998; Weick, 1995). Filmmaker George Lucas, who at one point in his career was CEO of eight corporations at the same time, once quipped that, 'Trust starts at the top and trickles down' (Kramer, 2009b).

Recognizing the central role leaders play in the trust-building process, organizational scholars have attempted to explore the nature and impact of this relationship (Dirks, 2006; Dirks and Skarlicki, 2004). In an attempt to assess the state of our knowledge, Dirks and Ferrin (2002) performed a useful meta-analysis of nearly four decades of research on the positive effects of trust on leadership effectiveness and organizational performance. They found that trust in leaders had a significant relationship with respect to a variety of important outcomes, including constituents' commitment to a leader's decisions, their commitment to the organization itself, reductions in reported intentions to turnover jobs, enhanced job performance and satisfaction, and increased levels of organizational citizenship behaviors.
In a similar vein, Davis et al. (2000) found that trust in management was associated with improved sales and profits, along with reduced turnover. In yet another study, Dirks (2000) reported a relationship between players' trust in their head coach and winning in the National Basketball Association. Finally, and more recently, Grant and Sumanth (forthcoming) found that trust in leaders was associated with enhanced prosocial motivations and behaviors among employees, at least within the context of service organizations.

There are several mechanisms by means of which leaders create collective trust. From an attributional perspective, leaders garner a large share of the causal credit for things that happen - and don't happen - inside organizations. This association is so powerful that Hackman (2002) characterized the tendency as the leader attribution error. While the leadership attribution error can get us into trouble (eg, by misattributing the reasons for organizational failures), in the case of trust-building initiatives, it's a bias that can be exploited positively. A leader can use the error to heighten the sense that trust is reasonable because he or she will make sure the requisite grounds for trustworthiness are created and maintained. When I talked to someone who had worked on a film crew with Clint Eastwood, he stated, 'There is a sense of everyone knowing just what they are supposed to be doing and doing it well. And everyone knows everyone else is really good at his or her job. So, it's very efficient; you don't have to talk a lot about what needs to be done. There's a sense of every one trusting everyone else. It's a very professional and very pleasant atmosphere in which to work'. Eastwood himself has stated, 'You're always confident when you have people [around you] who are good and who know your shorthand. Because there's understanding there, a shared history. These people understand completely - sometimes without any words 
at all - what you want' (cited in Kramer, 2009a).

A second way in which leaders help create trust is through the management of meaning (Weick, 1993). When I interviewed employees at Whole Foods, they said the emphasis on the importance of trust and being trusted was palpable - and largely the results of founder John Mackay's efforts to inculcate and support it. People felt empowered to act on the basis of that presumptive trust and, equally important, were committed to reinforcing and supporting it. (In contrast, I should note, employees I interviewed at HP under the leadership of CEO Carly Fiorina felt that words like trust, cooperation and teamwork had become hollow, mindless mantras.) The disconnection between rhetoric and reality, in fact, was palpable to students. When Fiorina visited the Stanford Business School, she gave a rousing talk regarding the importance of trusting people and getting them to trust you in return. Yet, when I interviewed executives and managers at HP under her (some who had listened to the very same talk I had), they said it was as if there were, as one put it, 'two different Carly's ... one the stage performer who knows all the right lines. And the second the real Carly you see during your day-to-day interactions at HP. And then it's not about trust and rapport with the people at all. It's about the results you produce - and that's it. Produce or get out of the way'.

In concluding my consideration of the various intra-organizational influences on collective trust, I would be remiss if I failed to mention some of the more macro-level, structural determinants. If collective trust is largely about individuals' diffuse expectations and generalized beliefs regarding other organizational members' trustworthiness, then any formal structures or procedures that provide a basis for inferring or presuming that others are likely to behave in a trustworthy fashion should enhance such trust.
This argument is based on evidence that members' trust within organizations is affected by members' confidence in the procedural and distributive fairness of outcomes (eg, Brockner and Sigel, 1996; Brockner et al., 1997; Tyler and Degoey, 1996). Effective monitoring and sanctioning systems constitute possible mechanisms for providing such reassurance. To the extent such mechanisms are perceived as credible or effective deterrents to breaches of the collective trust (Lewicki and Bunker, 1995), then they will provide the requisite assurance that one's own trusting behaviors are neither risky nor foolish. If people believe that others are doing their fair share in terms of the social contract, it makes it easier for them to do so as well (Messick et al., 1983). Thus, for example, the presence of sanctioning systems that are perceived to be efficacious and fair provides a useful deterrent mechanism (Yamagishi and Yamagishi, 1994) that, in turn, provides assurance.

In addition to explicit deterrents, hedges constitute another interesting mechanism for mitigating the perceived risks associated with initial acts of trust (Meyerson et al., 1996). A hedge operates to reduce the perceived risks and vulnerabilities of trust by reducing perceived dependence on a given actor or outcome. In other words, hedges protect individuals against the risks of misplaced trust, especially in situations where the perceived stakes are high. The existence of a hedge allows one to enter into a risky venture because there is a back up against disappointment or breach. In this respect, hedges function much like Best Alternatives to a Negotiated Agreement (BATNAs) in negotiations. As with BATNAs, hedges create a psychological 'fail safe' mechanism, thereby reducing perceived vulnerability to an acceptable level. As psychological devices, hedges are interesting because they imply an attitude that is somewhat equivocal: one trusts the other, but not completely. Hedges thus help jumpstart a trust 
development process and, if reinforced or reciprocated by others' subsequent trustworthy actions, become self-reinforcing.

\section{CONCLUSIONS AND CAVEATS}

In this paper, I have tried to indicate how we might conceptualize individuals' generalized trust in other organizational members as a form of positive social expectation, an expectation predicated upon their perceptions of, and beliefs about, the attributes of the collective as a whole and/or its average or 'prototypic' member. In trying to locate this particular conceptualization of trust within the large and diverse network of extant constructs in the literature, I would like to emphasize a few points of conceptual linkage and affinity with other theoretical perspectives.

First, and perhaps foremost, collective trust should be viewed as a particular type of social representation held by the individuals within a social system. As Brewer and Gardner (1996) argued in their influential analysis of individuals' cognitive selfrepresentations, the self-concept appears to consist of at least three basic levels, which they characterized as the individual self, the interpersonal or relational self, and the collective self. As numerous experiments have demonstrated, the sense of self that is salient or activated in a given social situation is likely to be influenced by a variety of social and situational cues. When these cues are primed, individuals' behavior changes accordingly (see Kramer and Brewer (1986) and Kramer et al. (1996) for reviews of this experimental literature).

One implication of the social information processing model presented here - which construes individuals as vigilant social auditors - is that individuals will pay considerable attention to cues indicative of others' trustworthiness or lack of trustworthiness. Some cues will reassure people that trust in their situation makes sense, whereas other cues will activate concerns regarding others' trustworthiness. In this respect, the arguments presented here resonate with recent efforts by Gambetta and his colleagues to develop a sign theory of trust (Bacharach and Gambetta, 2001; Gambetta and Hamill, 2005). As Gambetta and Hamill (2005) note in a recent articulation (and empirical investigation) of this perspective, it is assumed that 'trusters acquire, in various ways, an idea of which trust-warranting properties a trustee needs to be trustworthy in a given game (as well as the obverse properties that make a trustee untrustworthy' (p. 6). These trust warranting properties include such things as the trustee's honesty and benevolence.

The problem with such trust-warranting properties, Gambetta and Hamill go on to point out, is that they can never be assessed directly through observation. They must, therefore, be inferred from the available evidence at hand. As a consequence, social perceivers are forced to assess a trustee's trustworthiness 'by evaluating observable signs of him that the truster believes to be correlated with the unobservable trustwarranting properties' (p. 7). With respect to dyadic-level trust dilemmas, Gambetta and Hamill note, such signs include any observable feature of the individual trustee, including verbal and non-verbal indicators, physical signs such as clothing and other props, as well as a host of other indicators that might be construed as diagnostic of an underlying trust-warranting property.

In the case of collective contexts, I would argue, we also rely on a rich and complex set of ambient environmental signs when trying to calibrate the general level of trustworthiness of a group or collective to which we belong. These ambient signs include the kinds of structural, procedural, and social indicators described above, and that are construed as probative evidence of other people's willingness to behave in a trustworthy fashion. Such signs represent, in a sense, proxies for individuating knowledge about specific trustees. In that sense, they resemble 
stereotypes - but positive stereotypes rooted in a considerable body of converging, supportive evidence of underlying general trustworthiness.

I would be remiss if I failed to mention that there is a potential dark side to this argument as well. Every sign of trustworthiness can be faked - and those that are considered most reliable and most diagnostic may be the easiest to fake (Kramer, 1998, 2009d). As Gambetta and Hamill (2005) point out, skillful impersonators can always mimic the outward signs or appearance of trustworthiness, thus lulling potential victims into a false sense of security. Are there equivalents of such mimicry or deception at the collective level? Enron might be taken as one candidate (Kramer, 2002). In a Wall Street Journal article entitled 'En-ruse?', that appeared shortly after the collapse of Enron, it was reported that in 1998 more than 70 Enron employees were asked by top management to go to an empty trading floor and pose as busy sales representatives to impress a group of Wall Street analysts who were visiting the company's headquarters. According to one employee who had participated in the lie, 'We actually brought in computers and phones, and they told us to act like we were typing or talking on the phone when the analysts were walking through. They told it us it was very important for us to make a good impression, and if the analysts saw that the operation was disorganized, they wouldn't give the company a good rating. 'To enhance this illusion, the employees even brought in personal pictures of loved ones to adorn the tops of their desks. Although the whole charade lasted only $10 \mathrm{~min}$, it was enough time to create the impression of a dynamic, flourishing trade floor.

A more recent - and perhaps even more compelling example because of the sheer scale and longevity of the deception - is the fraud perpetuated by Bernard Madoff (Kramer, 2009d). He created an enormous institutionalized deception that fooled a vast collective of associates and investors. As one broker who had been lulled into investing with Madoff, 'There was something about this person, pedigree, and reputation that inspired trust'. Madoff created an illusion of personal and institutional trustworthiness on an audacious scale: he successfully cultivated the right social networks, acquired the right credentialing friends and associates, created and managed what seemed to be flourishing business offices, and located himself and his institutions in reassuring, high prestige locations. Government figures sought his advice and he was a frequent commentator and expert on financial affairs. In short, all the signs of professional and personal trustworthiness were there - they were just all faked. Thus, a little prudent paranoia and due diligence are also warranted, especially in situations where the costs of misplaced or mistaken trust are high.

Another point of conceptual connection of the present arguments is with Robert Putnam's (1993) analysis of the relationship between the levels of trust in a social system and the social capital available to its members. As I hope it is already clear, collective trust has a number of benefits from the standpoint of organizational effectiveness and functioning. First and foremost, it greatly reduces transaction costs. Individuals do not have to negotiate trust, but instead can simply assume trustworthiness (to the extent sufficient indicators are in place). In addition, individuals should be able to cooperate and coordinate more easily and effectively. In this case, collective trust constitutes a vital organizational resource. Loosely speaking, it constitutes a useful psychological form of organizationally bounded social capital (Putnam, 1993).

As a potential form of social capital, the question can be raised as to how resilient or reliable might be such trust. The issue of the resilience of any given form of trust is important. A number of scholars have noted 
the seeming fragility of trust in many situations, noting that trust is often 'hard won, but easily lost'. In the case of the various bases of collective trust identified here, the jury is still out. However, it is important to note that it is not necessary to assume that a particularly strong or cohesive bond or positive expectation needs to exist among all the members of the collective in order for trust to work. As Deutsch (1958) suggested in this regard, 'Mutual trust can occur even under circumstances where the people involved are not overly concerned with each other's welfare, provided that the characteristics of the situation are such as to lead one to expect one's trust to be fulfilled' (p. 279).

As an empirical question, nonetheless, it is not clear from the available experimental and qualitative evidence presented in this paper just how people weight these various factors (ie, which are more or less important in their assessments of how 'safe' it is to trust). We might hypothesize that more formalized and institutionalized factors tend to trump social or relational factors in causal importance - especially in large, differentiated, and socially heterogeneous collectives. I assert this as a hypothesis only because I suspect most of us would view well-conceived structural and procedural mechanisms as more stable and enduring sources of assurance than their more subtle (and possibly transient) psychological cousins. But this issue remains an open question, and one that merits empirical scrutiny.

Perhaps the most important implication of a fully developed theory of collective trust, including a deep understanding of its antecedents and consequences, is that it provides the foundation for a theory of organizational trustworthiness. We need more trustworthy organizations - organizations that reliably produce competent results and that are motivated not only to 'do no evil', but also to do good.

\section{Acknowledgments}

An earlier version of this paper was presented at the 2009 Ruffin Summit on Public Trust in Business, held at the University of Virginia's Darden School of Business in Charlottesville, Virginia. I am extremely grateful to the organizers of that conference and the conference participants for their helpful feedback and suggestions. I am particularly grateful to the Brian Moriarty, Andy Wicks, and Jared Harris for their comments and efforts in improving these ideas. The development of these ideas was supported by funds from the Kennedy School of Government and the Stanford Business School.

\section{References}

Arrow, K. (1974) The Limits of Organisation, Norton, New York.

Bacharach, M. and Gambetta, D. (2001) 'Trust in signs', in K.S. Cook (ed.), Trust in Society, Russell Sage Foundation, New York, pp. 148-184.

Bachmann, R. and Zaheer, A. (2006) Handbook of Trust Research, Edward Elgar, Northampton, MA.

Barber, B. (1983) The Logic and Limits of Trust, Rutgers University Press, New Brunswich, NJ.

Bendor, J., Kramer, R.M. and Stout, S. (1991) 'When in doubt: Cooperation in the noisy prisoner's dilemma', Journal of Conflict Resolution, 35, 691-719.

Boon, S.D. and Holmes, J.G. (1991) 'The dynamics of interpersonal trust: Resolving uncertainty in the face of risk', in R.A. Hinde and J. Groebel (eds.), Cooperation and Prosocial Behavior, Cambridge University Press, New York.

Boyle, R. and Bonacich, P. (1970) 'The development of trust and mistrust in mixed-motives games', Sociometry, 33, 123-139.

Brewer, M.B. (1981) 'Ethnocentrism and its role in interpersonal trust', in M.B. Brewer and B.E. Collins (eds.), Scientific Inquiry and the Social Sciences, Jossey-Bass, New York.

Brewer, M.B. (1996) 'In-group favoritism: The subtle side of intergroup discrimination', in D.M. Messick and A. Tenbrunsel (eds.), Behavioral Research and Business Ethics, Russell Sage, New York.

Brewer, M.B. and Gardner, W. (1996) 'Who is this 'we'? Levels of collective identity and selfrepresentation', Journal of Personality and Social Psychology, 21, 1288-1296.

Brockner, J. and Sigel, P.A. (1996) 'Understanding the interaction between procedural and distributive 
justice: The role of trust', in R.M. Kramer and T.R. Tyler (eds.), Trust in Organisations, Sage Publications, Thousand Oaks, CA.

Brockner, J., Siegel, P.A., Daly, J.P. and Tyler, T. (1997) 'When trust matters: The moderating effects of outcome favorability', Administrative Science Quarterly, 43, 558-583.

Bromiley, P and Cummings, L.L. (1995) 'Transaction costs in organisations with trust', in R. Bies, R. Lewicki and B. Sheppard (eds.), Research and Negotiations in Organizations, Vol. 5, JAI Press, Greenwich, CT, pp. 219-247.

Burt, R. and Knez, M. (1995) 'Kinds of third-party effects on trust', Journal of Rationality and Sociology, 7, 255-292.

Cook, K., Kramer, R.M., Thom, D.H., Stepanikova, I., Mollborn, S.B. and Cooper, R.M. (2004) 'Trust and distrust in physician-patient relationships: Antecedents and consequences', in R.M. Kramer and K.S. Cook (eds.), Trust in Organizations: Dilemmas and Approaches, Russell Sage, New York, pp. 65-98.

Cook, K.S. (2001) Trust in Society, Russell Sage Foundation, New York.

Cook, K.S., Hardin, R. and Levi, M. (2005) Cooperation without Trust, Russell Sage Foundation, New York.

Crano, W.D. and Brewer, M.B. (2002) Principles and Methods of Social Research, 2nd edn., Erlbaum, Mahwah, NJ.

Creed, W.D. and Miles, R.E. (1996) 'Trust in organisations: A conceptual framework linking organisational forms, managerial philosophies, and the opportunity costs of controls', in R.M. Kramer and T.R. Tyler (eds.), Trust in Organisations, Sage, Thousand Oaks, CA.

Davis, J., Schoorman, F.D., Mayer, R.C. and Tan, H. (2000) 'The trusted general manager and business unit performance: Empirical evidence of a competitive advantage', Strategic Management Journal, 21, 543-576.

Dawes, R.M. (1994) House of Cards: Psychology and Psychotherapy Built on Myth, Free Press, New York.

Deutsch, M. (1958) 'Trust and suspicion', Journal of Conflict Resolution, 2, 265-279.

Dirks, K.T. (2000) 'Trust in leadership and team performance: Evidence from NCAA basketball', Journal of Applied Psychology, 85, 1004-1012.

Dirks, K.T. (2006) 'Three fundamental questions regarding trust in leaders', in R. Bachmann and A. Zaheer (eds.), Handbook of Trust Research, Edward Elgar, Northhampton, MA, pp. 15-28.

Dirks, K.T. and Ferrin, D.L. (2002) 'Trust in leadership: Meta-analytic findings and implications for organizational research', Journal of Applied Psychology, 87, 611-628.

Dirks, K.T. and Skarlicki, D.P. (2004) 'Trust in leaders: Existing research and emerging issues', in
R.M. Kramer and K.S. Cook (eds.), Trust and Distrust in Organizations: Dilemmas and Approaches, Russell Sage Foundation, New York, pp. 21-40.

Fine, G. and Holyfield, L. (1996) 'Secrecy, trust and dangerous leisure: Generating group cohesion in voluntary organisations', Social Psychology Quarterly, 59, 22-38.

Fukuyama, F. (1995) Trust: The Social Virtues and the Creation of Prosperity, Free Press, New York.

Gabarro, J.J. (1978) 'The development of trust and expectations', in A.G. Athos and J.J. Gabarro (eds.), Interpersonal Behavior: Communication and Understanding in Relationships, Prentice Hall, Englewood Cliffs, NJ, pp. 290-303.

Gambetta, D. (1988) 'Can we trust trust?', in D. Gambetta (ed.), Trust: Making and Breaking Cooperative Relationships, Basil Blackwell, Cambridge, pp. 213-237.

Gambetta, D. and Hamill, H. (2005) Streetwise: How Taxi Drivers Establish Their Customers' Trustworthiness, Russell Sage Foundation, New York.

Granovetter, M. (1985) 'Economic action and social structure: The problem of embeddedness', American Journal of Sociology, 91, 481-510.

Grant, A.M. and Sumanth, J.J. (2009) 'Mission possible? The performance of prosocially motivated employees depends on manager trustworthiness', Journal of Applied Psychology, 94, 927-944.

Hackman, J.R. (2002) Leading Teams: Setting the Stage for Great Performances, Harvard Business School Press, Boston, MA.

Hardin, R. (2002) Trust and Trustworthiness, Russell Sage Foundation, New York.

Hume, D. (1969) Treatise on Human Nature, Penguin, Middlesex, UK.

Knez, M. and Camerer, C. (1994) 'Creating expectational assets in the laboratory: Coordination in 'weakest link' games', Strategic Management Journal, 15, 101-119.

Kollock, P. (1994) 'The emergence of exchange structures: An experimental study of uncertainty, commitment and trust', American Sociology Review, 100, 313-345.

Kramer, R.M. (1998) 'Paranoid cognition in social systems', Personality and Social Psychology Review, 2, 251-275.

Kramer, R.M. (2002) 'When paranoia makes sense', Harvard Business Review, 80, 62-71.

Kramer, R.M. (2009a) 'Clint Eastwood: A case study in creative leadership', Unpublished draft case, Stanford University, Palo Alto, CA.

Kramer, R.M. (2009b) 'George Lucas: A case study in creative leadership', Unpublished draft case, Stanford University, Palo Alto, CA. 
Pew Research Center for the People and the Press (1996) Trust and Citizen Engagement in Metropolitan Philadelphia: A Case Study, Pew, Washington, DC.

Pilisuk, M., Kiritz, S. and Clampitt, S. (1971) 'Undoing deadlocks of distrust: Hip Berkeley students and the ROTC', Journal of Conflict Resolution, 15, 81-95.

Pilisuk, M. and Skolnick, P. (1968) 'Inducing trust: A test of the Osgood proposal', Journal of Personality and Social Psychology, 8, 121-133.

Putnam, R.D. (1993) Making Democracy Work: Civic Traditions in Modern Italy, Princeton University Press, Princeton, NJ.

Salancik, G. and Pfeffer, J. (1978) 'A social information processing approach to job attitudes and task design', Administrative Science Quarterly, 23, 224-253.

Shapiro, D.L., Sheppard, B.H. and Cheraskin, L. (1992) 'Business on a handshake', Negotiations Journal, 8, 365-377.

Solomon, L. (1960) 'The influence of some types of power relationships and game strategies upon the development of interpersonal trust', Journal of Abnormal Social Psychology, 61, 223-230.

Tyler, T.R. and Degoey, P. (1996) 'Trust in organisational authorities: The influence of motive attributions on willingness to accept decisions', in R.M. Kramer and T.R. Tyler (eds.), Trust in Organisations, Sage, Thousand Oaks, CA.

Uzzi, B. (1997) 'Social structure and competition in interfirm networks: The paradox of embeddedness', Administrative Science Quarterly, 42, 35-67.

Weber, J.M., Malhotra, D. and Murnighan, J.K. (2005) 'Normal acts of irrational trust: Motivated attributions and the trust development process', in B.M. Staw and R.M. Kramer (eds.), Research in Organizational Behavior, Vol. 26, Elsevier Press, New York, pp. 75-102.

Weick, K.E. (1993) 'The collapse of sensemaking in organisations: The Mann Gulch disaster', Administrative Science Quarterly, 38, 628-652.

Weick, K.E. (1995) Sense Making in Organizations, Sage, Thousand Oaks, CA.

Whitener, E.M., Brodt, S.E., Korsgaard, M.A. and Werner, J.M. (2006) 'Managers as initiators of trust: An exchange relationship for understanding managerial trustworthy behavior', in R.M. Kramer (ed.), Organizational Trust: A Reader, Oxford University Press, New York, pp. 140-169.

Yamagishi, T. and Yamagishi, M. (1994) 'Trust and commitment in the United States and Japan', Motivation and Emotions, 18, 129-166.

Zucker, L.G. (1986) 'Production of trust: Institutional sources of economic structure, 1840-1920', in B.M. Staw and L.L. Cummings (eds.), Research in Organizational Behavior, Vol. 8, pp. 53-111. 